\title{
Fibronectin Biosynthesis in the Rat Aorta In Vitro Changes Due to Experimental Hypertension
}

Rola Saouaf, Izumi Takasaki, Elizabeth Eastman, Aram V. Chobanian, and Peter Brecher

Departments of Biochemistry and Medicine, Boston University School of Medicine, Boston, Massachusetts 02118

\begin{abstract}
This study was undertaken to determine if changes in fibronectin biosynthesis accompany the phenotypic changes that occur in aortic tissue following experimental hypertension. An in vitro procedure was developed to measure fibronectin synthesis in aortic rings obtained from normotensive or hypertensive rats. There was a three to sixfold increase in fibronectin biosynthesis by aortic rings taken from rats treated with deoxycorticosterone/salt for 7 and $21 \mathrm{~d}$, the change being more pronounced at $21 \mathrm{~d}$. In contrast, there was no major change at either time point in net incorporation into total protein. Studies comparing fibronectin biosynthesis in aortic rings from Wistar rats and spontaneously hypertensive rats at ages between 10 and 40 wk showed increased fibronectin biosynthesis in older animals of both strains, but only slight differences between strains. Studies using rats infused with angiotensin II showed a correlation between blood pressure elevation and increased aortic fibronectin biosynthesis. Western blot analysis of aortic extracts showed that the fibronectin content was increased in the hypertensive models. The in vitro procedure for measuring fibronectin biosynthesis appears to provide a reliable reflection of in vivo changes in fibronectin expression, and the methodology could prove useful for studying the factors influencing protein expression in vascular tissue. (J. Clin. Invest. 1991. 88:1182-1189.) Key words: angiotensin • vascular • extracellular matrix • immunoprecipitation
\end{abstract}

\section{Introduction}

Vascular complications of several diseases are associated with changes in the extracellular matrix and accompanying intracellular changes in vascular cells (1). Since interactions between proteins of the extracellular matrix and cell receptors called integrins are known to influence cell structure, it is plausible that changes in the expression of components of the extracellular matrix could have a causative role in the development of the resulting vascular lesions. Several studies have indicated that vascular smooth muscle cells can undergo a change from a contractile to synthetic phenotype during atherosclerosis $(2,3)$, and models for such changes have been established using cul-

This work was presented in part at the American Heart Association Scientific Sessions, Dallas, TX, November 1990.

Address correspondence to Peter Brecher, Ph. D., Professor of Biochemistry, Boston University School of Medicine, 80 East Concord Street, Boston, MA 02118.

Received for publication 7 February 1991 and in revised form 16 May 1991.

J. Clin. Invest.

(c) The American Society for Clinical Investigation, Inc.

$0021-9738 / 91 / 10 / 1182 / 08 \quad \$ 2.00$

Volume 88, October 1991, 1182-1189 tured cells (4). Fibronectin (FN) ${ }^{1}$, an important component of the extracellular matrix, was shown to interact with vascular smooth muscle cells in a manner influencing the interconversion between contractile and synthetic phenotypes (5). Interactions between fibronectin and the endothelial cell also induce functional changes in motility, morphology, and replication (6-8). Based on such studies performed with cultured cells, it is possible that fibronectin could modulate the function of vascular cells and perhaps have a direct influence on the development of vascular lesions.

Histochemical studies have documented the presence of fibronectin in aortic tissue, and changes in fibronectin content have been reported in different disease states, such as diabetes and atherosclerosis (9-13), although quantitation has been difficult due to the insoluble nature of the cellular fibronectin (14). Recently, a study by Glukhova et al. (15) showed that different alternately spliced forms of fibronectin are selectively localized in the intima and media, and following either balloon injury to the rat aorta or in human aortic atherosclerotic lesions, a selective accumulation of an alternatively spliced form of fibronectin was found within the intimal lesion.

Hypertension leads to morphological and functional changes in the vessel wall, and accompanying changes in the extracellular matrix have been documented (16-18). However, there is little information available on changes in vascular fibronectin expression with hypertension. In a recent study (19), we showed that steady-state mRNA levels for rat aortic fibronectin increased several-fold in deoxycorticosterone acetate (DOC)/ salt-treated and angiotensin II-infused rats and in the spontaneously hypertensive rat (SHR). An age-dependent increase in aortic fibronectin mRNA also was shown in those studies (19). In this study, we have used an in vitro procedure for measuring protein biosynthesis in aortic rings to determine if the biosynthesis of aortic fibronectin is increased in experimental hypertension concomitant with the previously documented changes in steady state mRNA. In addition, Western blot analysis was used to measure the amount of fibronectin contained in aortic tissue from normotensive and hypertensive rats.

\section{Methods}

Animals. Male Wistar rats, 250-300 g, were obtained from Charles River Breeding Laboratories, Wilmington, MA. DOC/salt hypertension was induced as previously described (20). Briefly, deoxycorticosterone pellets $(100 \mathrm{mg})$ were implanted subcutaneously into uninephrectomized rats, and saline was substituted for drinking water. Control animals were uninephrectomized but not given DOC/salt treatment. Angiotensin II-induced hypertension was achieved by subcutaneous infusion of angiotensin II (125 ng/min) using an Alzet Mini-Osmotic pump. (Alza Corp., Palo Alto, CA). SHR were purchased from the Charles River Breeding Laboratories. Systolic blood pressure was mea-

1. Abbreviations used in this paper: DOC, deoxycorticosterone acetate; FN, fibronectin; SHR, spontaneously hypertensive rat; TGF- $\beta$, transforming growth factor- $\beta$. 
sured by tail cuff plethysmography and a photoelectric cell detector as described previously (21).

Tissue. Animals were killed with an overdose of sodium pentobarbital. Aortae were removed, taking care to avoid stretching or compression of the tissue, and placed into ice-cold buffer containing $137 \mathrm{mM}$ $\mathrm{NaCl}, 2.7 \mathrm{mM} \mathrm{KCl}, 4.3 \mathrm{mM} \mathrm{Na} \mathrm{HPO}_{4} \cdot \mathrm{H}_{2} \mathrm{O}, 1.4 \mathrm{mM} \mathrm{KH}_{2} \mathrm{PO}_{4}(\mathrm{pH}$ 7.4), and $11 \mathrm{mM}$ glucose. The region of the aorta extending from the arch to the diaphragm was used in all studies. Aortae were carefully cleaned of periadventitial tissue and seven to eight rings of $\sim 5 \mathrm{~mm}$ length were obtained from the arch and thoracic region of each aorta. The cleaning and preparation of rings were performed with care to avoid unnecessary damage to the vessel. The procedure routinely took $\sim 10 \mathrm{~min}$ per aorta. The rings prepared from a single rat aorta were placed into $2 \mathrm{ml}$ of DMEM without L-methionine (Gibco Laboratories, Grand Island, NY) that was supplemented with $8 \mu \mathrm{M}$ L-methionine and $200 \mu \mathrm{Ci}^{35} \mathrm{~S}$-methionine (New England Nuclear, Boston, MA). Incubations were at $37^{\circ} \mathrm{C}$ for $5 \mathrm{~h}$ with constant shaking in an atmosphere of $95 \%$ air and $5 \% \mathrm{CO}_{2}$. The aortic rings were removed from incubation media at the end of the incubation period, washed several times in PBS, and then weighed and frozen in liquid nitrogen. The weights of the aortic rings after incubation were considered as the aortic wet weight in the analysis of data. The incubation medium was stored at $-70^{\circ} \mathrm{C}$.

Aortae were homogenized using a motor driven glass-glass apparatus in PBS containing aprotinin ( 50 trypsin inhibitory units/ml), leupeptin (10 mM), pepstatin A (1 mM), and PMSF (1 mM), at a 20:1 ratio of buffer volume to tissue wet weight. The homogenate was centrifuged at $25,000 \mathrm{~g}$ for $20 \mathrm{~min}$, and the supernatant was removed and saved. The pellet was resuspended in $4 \%$ SDS, the resuspension heated at $100^{\circ} \mathrm{C}$ for $4 \mathrm{~min}$, and then centrifuged at $12,000 \mathrm{~g}$ for $5 \mathrm{~min}$. This supernatant, designated as the SDS extract, was removed and saved. All samples were stored at $-70^{\circ} \mathrm{C}$. Protein concentrations were obtained by using the BCA protein assay reagent kit by Pierce Chemical Co., Rockford, IL. In designated experiments, the initial pellet was extracted with $2 \%$ deoxycholate before extraction with $4 \%$ SDS.

Immunoprecipitation. An aliquot (100-200 $\mu \mathrm{l})$ of tissue extract containing $300 \mu \mathrm{g}$ protein was added to $800 \mu \mathrm{l}$ of a solution containing $2.5 \%$ Triton X-100, $190 \mathrm{mM} \mathrm{NaCl}, 6 \mathrm{mM}$ EDTA, $50 \mathrm{mM}$ Tris- $\mathrm{HCl}$ (pH 7.4), and 0.25 mM PMSF. A goat, anti-human polyclonal antibody to fibronectin (F-1509; Sigma Chemical Co., St. Louis, MO) was added ( $20 \mu \mathrm{l}, 660 \mu \mathrm{g}$ protein), and the mixture incubated overnight at $4^{\circ} \mathrm{C}$. Samples were centrifuged at $12,000 \mathrm{~g}$ for $2 \mathrm{~min}$ at $4^{\circ} \mathrm{C}$ and the supernatant was transferred to a clean microcentrifuge tube. $300 \mu \mathrm{l}$ of a 1:1 suspension of protein A-Sepharose CL-4B (Pharmacia Fine Chemicals, Piscataway, NJ) was added and incubated using end-over-end mixing at room temperature for $2 \mathrm{~h}$. Samples were then centrifuged for $10 \mathrm{~s}$ and the supernatant aspirated. The precipitated beads were washed four times with a solution of $0.1 \%$ Triton X-100, $0.02 \%$ SDS, $150 \mathrm{mM}$ $\mathrm{NaCl}, 5 \mathrm{mM}$ EDTA, $50 \mathrm{mM}$ Tris-HCl, pH 7.4, 0.2 mM PMSF, and two additional times with a similar solution lacking detergents. The final pellet was resuspended in $100 \mu \mathrm{l}$ of an SDS reducing buffer and boiled for $4 \mathrm{~min}$. The beads were then centrifuged and the supernatant was collected and saved for subsequent analysis.

For analysis of the incubation medium, immunoprecipitation was done following concentration of the protein by TCA precipitation. For those studies, $80 \mu \mathrm{g} \mathrm{BSA}$ was added to $1 \mathrm{ml}$ of sample before mixing with $100 \mu \mathrm{l}$ of TCA $(100 \%)$. After incubation on ice for $30 \mathrm{~min}$, the sample was centrifuged at $12,000 \mathrm{~g}$ for $15 \mathrm{~min}$, washed with $5 \%$ TCA and recentrifuged, and finally resuspended in $100 \mu \mathrm{l}$ of $4 \%$ SDS. An aliquot $(50 \mu \mathrm{l})$ of this resuspension was added to $950 \mu \mathrm{l}$ of the solution used for immunoprecipitation.

Gel electrophoresis and immunoblotting. Proteins were analyzed by SDS-PAGE as described by Laemmli (22) using the Mini-Protean II dual slab cell apparatus (Bio-Rad Laboratories, Richmond, CA). For analysis of methionine incorporation into protein, the separating gels were of $7.5 \%$ acrylamide. Gels were vacuum/heat dried and exposed to Kodak X-Omat AR x-ray film. Exposure times varied from 1 to $5 \mathrm{~d}$. For Western blot analysis, a Trans Blot apparatus (Bio-Rad) was used.
Transfer onto nitrocellulose was done at $4^{\circ} \mathrm{C}$ for $14 \mathrm{~h}$ in $20 \mathrm{mM}$ Tris, $200 \mathrm{mM}$ glycine, and $20 \%$ methanol. Immunological detection was performed using goat anti-human polyclonal antibody to fibronectin after pretreatment of the nitrocellulose support with $10 \%$ Carnation evaporated milk for $1 \mathrm{~h}$. Subsequent analysis used an anti-goat IgG horseradish peroxidase conjugate (Sigma Chemical Co., St. Louis, MO) as a second antibody, and chemiluminescence emitted from luminol oxidized by peroxidase was used as a detection method (ECL Western blotting detection system; Amersham International, Amersham, UK). The first antibody was used at a dilution of 1:3,000 and the second antibody at a 1:75,000 dilution. The general protocol was similar to that described in the instructions provided by the supplier. When the monoclonal antibody directed towards the EIIIA insert provided to us by Dr. Zardi, Cell Biology Laboratory, Instituto Nazionale per la Ricersa sul Cancro, Genova, Italy, (protein concentration, $2.1 \mathrm{mg} / \mathrm{ml}$ ) was used as the first antibody (23), the antibody was diluted 1:300 and an anti-mouse IgG horseradish peroxidase conjugate (Sigma) was used as the second antibody.

Quantitation of radioactivity. Quantitation of radioactive fibronectin was performed by cutting out the fibronectin region on the dried gel as identified by radioautography, adding $5 \mu \mathrm{l}$ water and $10 \mathrm{ml}$ of $5 \%$ Protosol/Econofluor solution (DuPont/NEN, Boston, MA), and incubating the samples overnight at $37^{\circ} \mathrm{C}$. Radioactivity was then determined by scintillation counting.

Incorporation of labeled methionine into total protein was determined by a filtration procedure. $10-20 \mu$ l of the tissue fraction was added to $5 \mathrm{ml}$ of $10 \% \mathrm{TCA}$, and incubated on ice for $30 \mathrm{~min}$. Solutions were then vacuum filtered onto GF/C glass filters (Whatman Inc., Clifton, NJ). The filters were washed four times with $1 \mathrm{ml}$ of 5\% TCA and a final wash with $95 \%$ ethanol. The filters were then dried and radioactivity determined by scintillation counting.

Statistical analysis. Values are listed as mean \pm SEM. Statistically significant differences were determined using the one way analysis of variance, followed by the Dunnett $t$ test.

\section{Results}

Preliminary experiments using rat aortic rings showed that rat aortic rings were metabolically active with respect to protein biosynthesis. Fig. 1 shows the SDS-PAGE profiles of ${ }^{35} \mathrm{~S}-\mathrm{me}$ thionine incorporation into proteins derived from the incubation medium and aortic tissue extracts after a 5-h incubation period, and of the corresponding immunoprecipitates using a
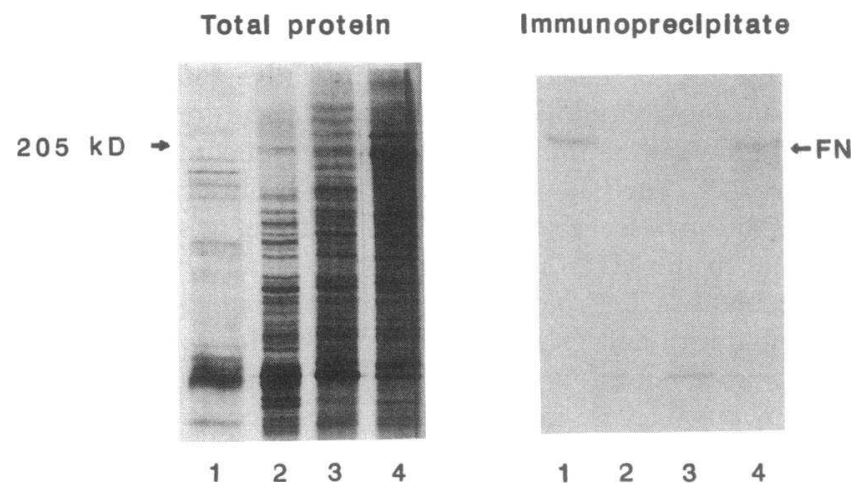

Figure 1. Distribution of radiolabeled protein and fibronectin in aortic fractions. Aliquots of incubation media $(I M) ; 25,000 \mathrm{~g}$ supernatant, (SUP); deoxycholate extract, (DOC); and SDS extract (SDS) were analyzed by SDS-PAGE using $71 / 2 \%$ gels. Incubation time was $5 \mathrm{~h}$. Comparable aliquots were immunoprecipitated using a goat anti-human polyclonal antibody as described in Methods. The aliquots used represent $5 \%$ of the total incubation media, and $0.9-1.0 \%$ of the tissue extracts. (1) IM; (2) SUP; (3) DOC; (4) SDS. 


\begin{tabular}{|c|c|c|c|c|c|c|c|}
\hline \multirow[b]{2}{*}{$\begin{array}{l}\text { Treatment } \\
\text { group }\end{array}$} & \multirow[b]{2}{*}{$n$} & \multirow[b]{2}{*}{$\begin{array}{l}\text { Blood } \\
\text { pressure }\end{array}$} & \multirow[b]{2}{*}{$\frac{\text { Heart wt }}{\text { Body wt }}$} & \multirow[b]{2}{*}{$\begin{array}{l}\text { Aortic } \\
\text { wet wt }\end{array}$} & \multirow[b]{2}{*}{$\frac{\text { Aorta wt }}{\text { Body wt }}$} & \multicolumn{2}{|c|}{ Aortic protein content } \\
\hline & & & & & & Supernate & SDS extract \\
\hline & & $m m H g$ & $\times 10^{3}$ & $m g$ & $\times 10^{4}$ & $m g / a o r t a$ & $m g / a o r t a$ \\
\hline Control (7 d) & 4 & $120 \pm 3.5$ & $3.2 \pm 0.1$ & $59.7 \pm 2.9$ & $2.0 \pm 0.1$ & $0.88 \pm 0.16$ & $1.39 \pm 0.09$ \\
\hline DOC/salt (7 d) & 5 & $150 \pm 6.4^{*}$ & $3.5 \pm 0.1$ & $68.6 \pm 3.0$ & $2.4 \pm 0.1^{\ddagger}$ & $1.42 \pm 0.10$ & $1.76 \pm 0.07^{\ddagger}$ \\
\hline Control (21 d) & 4 & $128 \pm 2.8$ & $3.0 \pm 0.2$ & $72.7 \pm 1.9$ & $2.0 \pm 0.1$ & $1.33 \pm 0.05$ & $1.56 \pm 0.05$ \\
\hline DOC/salt (21 d) & 4 & $174 \pm 6.9^{*}$ & $4.3 \pm 0.1^{8}$ & $99.0 \pm 5.8^{*}$ & $3.2 \pm 0.2^{8}$ & $2.68 \pm 0.29^{*}$ & $2.79 \pm 0.19^{8}$ \\
\hline
\end{tabular}

Values are means $\pm \mathrm{SEM} ;{ }^{\ddagger} P<0.05 ;{ }^{*} P<0.01 ;^{\S} P<0.001$.

polyclonal antibody directed towards fibronectin. The distribution of newly formed fibronectin among the different fractions was consistently greatest for the fraction obtained using $4 \%$ SDS, which comprised $\sim 60 \%$ of total radiolabeled fibronectin. About $15 \%$ was released into the medium, and the remainder was primarily in the deoxycholate extract.

Table I summarizes the comparative data on groups of animals treated with DOC/salt for 7 or $21 \mathrm{~d}$ and the appropriate age-matched controls. Systolic blood pressure was significantly higher in the treated animals even after $7 \mathrm{~d}$ (150 vs. 120 $\mathrm{mmHg}$ ) and by $21 \mathrm{~d}$ the DOC/salt-treated group had systolic pressures that averaged $174 \mathrm{mmHg}$. Both heart weight and aortic weight increased progressively with treatment, and the ratios with respect to body weight were consistently higher in the treated groups. The amount of soluble protein in both the supernatant (from the original aortic homogenate) and SDS extract was consistently greater in hypertensive vessels. This increase was proportionately greater than the increased wet weight and could reflect increased intracellular or extracellular protein.

Comparative studies between normal rat aorta and aortic tissue from hypertensive animals were performed using a protocol where two animals from each group were killed on the same day. The SDS extract obtained immediately after centrifugation of the homogenized tissue, which effectively combined the extracts using deoxycholate and SDS shown in Fig. 1, was used for the biochemical comparisons shown in Fig. 2 and the subsequent tables.

Fig. $2, A, B$, and $C$, shows representative data on ${ }^{35} \mathrm{~S}$-methionine incorporation into total protein and immunoprecipitable fibronectin in the aortic SDS extracts of control and 21-d treated rats. Each lane contains protein from incubated rings derived from a separate animal. The profile of total radioactive protein in the SDS fraction suggests that both high and low molecular weight proteins were made at about equivalent levels in control and DOC-treated animals. However, after immunoprecipitation of fibronectin in those samples, there was an obvious increase in the amount of labeled fibronectin immunoprecipitated from the samples of DOC-treated animals (Fig. 2 B). Quantitative immunoprecipitation was confirmed by experiments showing that comparable amounts of labeled fibronectin were immunoprecipitated using levels of antibody ranging from 10 to $200 \%$ of the amount used under standard conditions $(660 \mu \mathrm{g})$. This was true using extracts from control or treated animals. If the gels containing the immunoprecipitated samples were stained directly for protein using Coomassie brilliant blue (Fig. $2 C$ ), it was possible to visualize protein in the region where fibronectin should be localized, particularly in the extracts from treated animals. This further indicated the efficacy of the immunoprecipitation procedure for quantitative analysis. The other bands on the gel are the IgG heavy chain $(50 \mathrm{kD})$ and two other Coomassie-positive bands that were present even if the SDS extract was omitted. Fig. $2 D$ shows representative immunoprecipitates from the incubation medium of aortic rings taken from control or 21-d DOC/salttreated rats. Increased secretion of radiolabeled fibronectin was clearly observed in the fractions from treated animals, consistent with the data obtained using the SDS extracts.

Table II summarizes the quantitative data on protein and fibronectin biosynthesis in the aortic rings. All data are expressed per 5-h incubation period. Two soluble extracts from

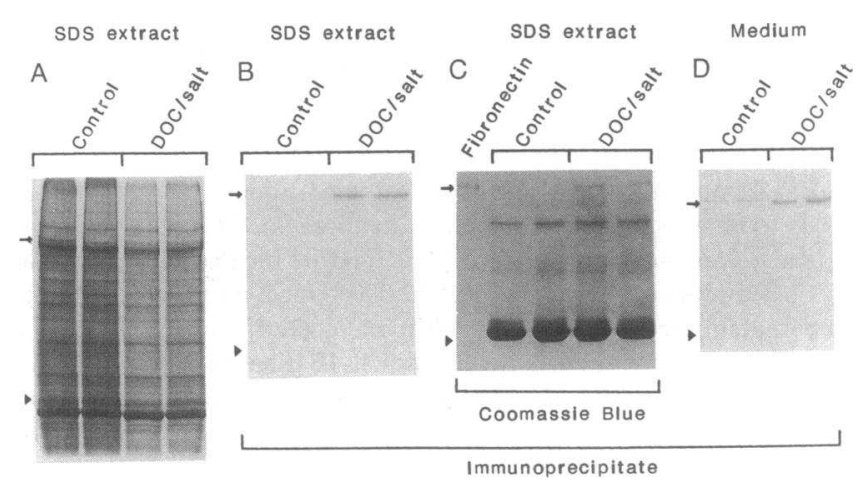

Figure 2. Comparison of ${ }^{35} \mathrm{~S}$-methionine incorporation into total protein and immunoprecipitable fibronectin in control and 21-d treated DOC/salt rats. $(A)$ Representative samples of the SDS extract from tissue of control and treated rats. Each lane contains the equivalent of $1 \%$ of the total SDS extract from a separate incubation containing aortic rings from a single rat. (B) Autoradiogram of immunoprecipitable radiolabeled fibronectin from the SDS extracts shown in $A$. Each lane contains the material derived from $60 \mu \mathrm{g}$ of protein in the original extract. $(C)$ Coomassie stained gel of the immunoprecipitable fraction of SDS extracts from control and DOC/salt treated animals. Each lane contains the material derived from $60 \mu \mathrm{g}$ of protein in the original extract. $(D)$ Representative samples of immunoprecipitates obtained from the incubation medium of aortae from control and DOC/salt-treated animals. Aliquots of the incubation medium were precipitated with TCA, and the resuspended samples immunoprecipitated with polyclonal antibody to fibronectin as described in Methods. Each lane contains the equivalent of $5 \%$ of the total incubation media. Arrows refer to the position of the molecular weight standards myosin and ovalbumin, having molecular masses of 205 and $46.5 \mathrm{kD}$, respectively. 
Table II. Effect of DOC/Salt Treatment on Aortic Fibronectin Biosynthesis

\begin{tabular}{|c|c|c|c|c|c|c|c|c|}
\hline \multirow{3}{*}{$\begin{array}{l}\text { Treatment } \\
\text { group }\end{array}$} & \multirow{3}{*}{$n$} & \multicolumn{4}{|c|}{${ }^{35} \mathrm{~S}$-Methionine incorporation into total protein } & \multicolumn{3}{|c|}{${ }^{35}$ S-Methionine incorporation into fibronectin } \\
\hline & & \multicolumn{2}{|c|}{ Supernate } & \multicolumn{2}{|c|}{ SDS extract } & \multicolumn{3}{|c|}{ SDS extract } \\
\hline & & pmol/fraction & $\mathrm{pmol} / \mathrm{mg}$ protein & pmol/fraction & $\mathrm{pmol} / \mathrm{mg}$ protein & $\begin{array}{l}\text { pmol/fraction } \\
\quad \times 10^{2}\end{array}$ & $\begin{array}{c}\text { pmol/mg protein } \\
\times 10^{2}\end{array}$ & 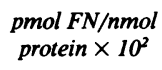 \\
\hline Control (7 d) & 4 & $322 \pm 70$ & $357 \pm 34$ & $782 \pm 23$ & $565 \pm 35$ & $4.53 \pm 0.3$ & $3.31 \pm 0.4$ & $5.81 \pm 0.45$ \\
\hline DOC/salt (7 d) & 5 & $480 \pm 33^{*}$ & $338 \pm 12$ & $907 \pm 29 *$ & $517 \pm 25$ & $16.7 \pm 2.8^{*}$ & $9.7 \pm 1.9^{*}$ & $18.6 \pm 3.4^{*}$ \\
\hline Control (21 d) & 4 & $413 \pm 34$ & $310 \pm 18$ & $889 \pm 34$ & $571 \pm 20$ & $9.84 \pm 0.4$ & $6.31 \pm 0.1$ & $11.1 \pm 0.31$ \\
\hline DOC/salt (21 d) & 4 & $707 \pm 77^{*}$ & $264 \pm 9$ & $1070 \pm 24^{\ddagger}$ & $387 \pm 20^{\ddagger}$ & $61.3 \pm 5.8^{\S}$ & $22.4 \pm 3.1^{\ddagger}$ & $57.6 \pm 6.1^{8}$ \\
\hline
\end{tabular}

Values are means \pm SEM; ${ }^{*} P<0.05 ;{ }^{\ddagger} P<0.01 ;{ }^{\S} P<0.001$.

aortic tissue were analyzed, the supernatant and the SDS extract. The amount of total protein in those fractions was greater in the treated animals than in controls, presumably reflecting the increased tissue wet weight. Incorporation of methionine into total protein did not change in either fraction after $7 \mathrm{~d}$ of treatment when the data were expressed as nanomoles of methionine incorporated into TCA-precipitable protein per milligram total protein. After $21 \mathrm{~d}$ of treatment, there was a decreased incorporation of methionine into protein for both the supernatant and SDS extract when expressed relative to tissue protein. However, in marked contrast to the comparisons based on total protein incorporation, incorporation into immunoprecipitable fibronectin was significantly increased after both 7 and $21 \mathrm{~d}$ of treatment. When the data were expressed as nanomoles of methionine incorporated into fibronectin relative to incorporation into total protein, there was threefold and fivefold increase at 7 and $21 \mathrm{~d}$ of treatment, respectively. These differences were even greater if the data were expressed as the amount of newly synthesized fibronectin per total fraction. This latter comparison is of some relevance since the cellular response in this animal model is primarily one of hypertrophy, not hyperplasia. Thus, the total number of vascular cells is probably similar in treated and control tissue, despite the increase in wet weight and tissue protein. Data are shown only for

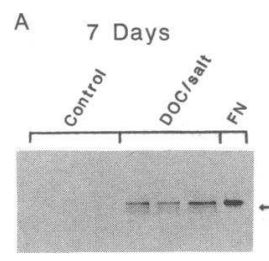

Polyclonal

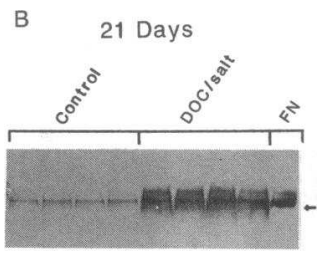

Polyclonal

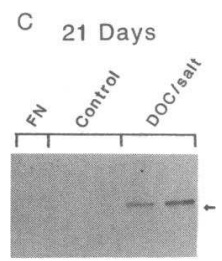

Monoclonal (EIIIA)
Figure 3. Western blot analysis of fibronectin in aortic SDS extracts from control and DOC/salt-treated animals. Each lane contains 20 $\mu \mathrm{g}$ protein from the SDS extract obtained from an individual rat aorta. $(A)$ Comparison of immunoreactive fibronectin in aortas of rats treated with DOC/salt for $7 \mathrm{~d}$ with age-matched uninephrectomized controls using the goat anti-human polyclonal antibody, which recognizes all forms of fibronectin. (B) Comparison of immunoreactive fibronectin in aortas of rats treated with DOC/salt for $21 \mathrm{~d}$ with agematched uninephrectomized controls using the goat anti-human polyclonal antibody. $(C)$ Comparable data using a mouse anti-rat monoclonal antibody directed specifically towards the sequence contained within the EIIIA insert. The lanes labeled FN standard contain $100 \mathrm{ng}$ of purified rat plasma fibronectin. the SDS extract, since almost no immunoprecipitable fibronectin was found in the supernatant fraction from control or treated animals.

Fig. 3, $A$ and $B$, depicts representative data using Western blot analysis to compare aortic fibronectin in control and hypertensive rats. Each lane represents the SDS extract from aortic rings of a single rat. There was a clearly visible increase in aortic fibronectin in the DOC/salt-treated animals after either 7 or $21 \mathrm{~d}$ of treatment. Densitometric analysis of data obtained from six animals in each age matched group after only $7 \mathrm{~d}$ of DOC/salt treatment showed a three to sixfold increase in immunodetectable fibronectin even though blood pressure levels did not exceed $160 \mathrm{mmHg}$ in the treated rats. After treatment for $21 \mathrm{~d}$, immunodetectable fibronectin remained almost sixfold greater than in nonhypertensive age-matched controls. Fig. $3 C$ shows a comparison between control and 21-d treated animals using a monoclonal antibody directed towards the EIIIA region of fibronectin, which is contained only in that alternatively spliced form of fibronectin thought to be made by nonhepatic cells and not found circulating in plasma. Again, there was an obvious increase in that form of fibronectin in the aortic fraction from DOC/salt-treated animals, but the sensitivity of the method was not sufficient to obtain quantitative data in control samples. The antibody had a very weak cross-reactivity towards purified plasma fibronectin (FN standard), indicating that the increased amounts of fibronectin in the extracts from treated animals did not originate solely from circulating protein.

A series of experiments were performed to determine if differences in fibronectin biosynthesis could be found between the SHR and age-matched control Wistar rats using 10,20, and 40-wk old animals. Table III summarizes the data obtained. Differences in blood pressure and heart weight/body weight ratios were as expected, and aortic weight/body weight ratios were consistently greater in the SHR. Total protein biosynthesis in the SDS extract was similar in both strains and when expressed relative to the protein concentration, there were only slight differences as a function of age. A significant difference between control and hypertensive animals with respect to fibronectin biosynthesis was found using 10-wk old animals, with a two to threefold increase being found in the vessels from hypertensive animals, analogous to the findings in the DOC/salt model. There was no significant increase in fibronectin biosynthesis in the SHR of older animals when paired with agematched normotensive controls nor did there appear to be major differences in overall protein biosynthesis. However, there 

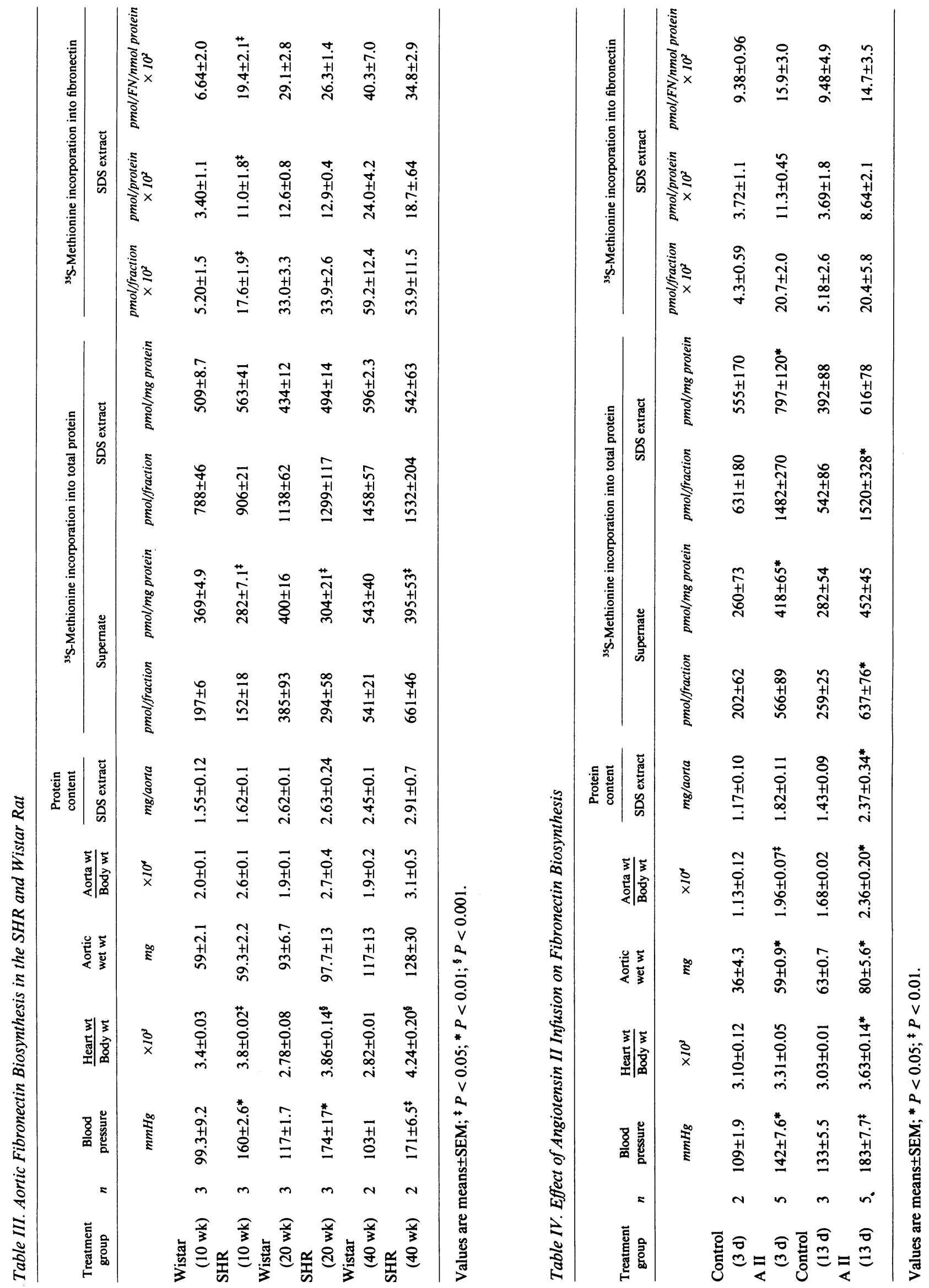
was a striking increase in aortic fibronectin biosynthesis within each strain as the animals aged from 10 to $40 \mathrm{wk}$, an increase that did not occur in overall protein biosynthesis. Thus, the ratio of fibronectin biosynthesis to total protein biosynthesis for 10-wk old Wistar rats $\left(6.64 \times 10^{-2}\right)$ was increased fourfold and sixfold in 20 and 40 -wk old Wistar animals. These relative changes were not as obvious for the SHR because of the higher rate of fibronectin biosynthesis in the 10-wk old animals.

Another hypertensive animal model used for these studies involved infusion of angiotensin II at pressor levels using an osmotic pump. This was done for either 3 or $13 \mathrm{~d}$, and the general protocol outlined above for measuring protein and fibronectin biosynthesis was followed. The results are summarized in Table IV. Animals infused with angiotensin II for $13 \mathrm{~d}$ were hypertensive and had increased heart and aortic wet weight. Animals infused for $3 \mathrm{~d}$ had only slightly elevated blood pressures when measured before killing the animals, but the increased aortic wet weight and a statistically insignificant increase in heart weight suggested that blood pressure levels were chronically elevated during the $3 \mathrm{~d}$ of treatment. Both protein and fibronectin biosynthesis increased as a result of angiotensin II infusion at both time periods studied, although interassay variability did diminish the statistical significance of the increase in fibronectin biosynthesis.

Western blot analysis of the aortic SDS extracts from animals infused with angiotensin II showed marked increases in fibronectin content even after only three days of treatment

A

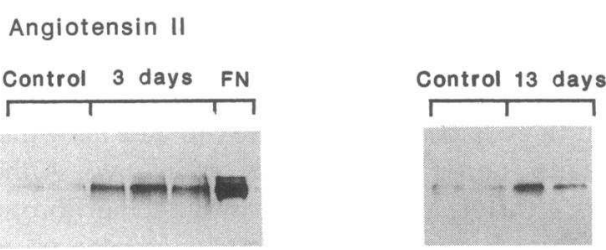

B

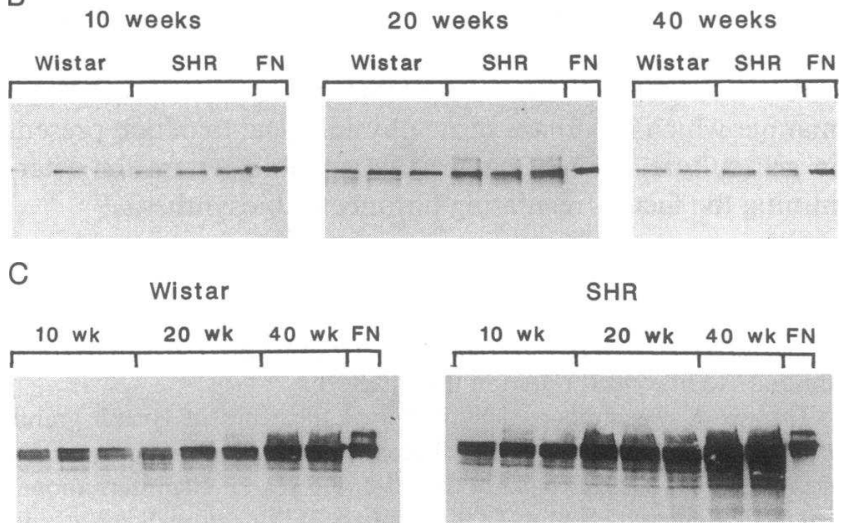

Figure 4. Western blot analysis of aortic SDS extracts from control and angiotensin II-infused animals and age-matched Wistar and SHR. Each lane contains $20 \mu \mathrm{g}$ of total protein from the SDS extract of a single aorta. All comparisons were made using the polyclonal antibody recognizing all forms of fibronectin. $(A)$ Treated animals were infused with angiotensin II for 3 or $13 \mathrm{~d}$. Comparisons are with agematched controls infused with saline for comparable periods. $(B)$ Comparison between age-matched Wistar and SHR at 10, 20, and 40 wk of age. $(C)$ Comparisons between Wistar rats of different ages and of SHR at different ages.
(Fig. $4 \mathrm{~A}$ ). The relative increases as determined by densitometry ranged from three to eightfold at either time of infusion and suggested major changes in the aortic extracellular matrix occurred rapidly in response to angiotensin II infusion. These changes also were seen in animals given the peptide for $13 \mathrm{~d}$, although the increases were not as marked as those observed at the earlier time. Comparisons between age-matched Wistar and SHR by Western blot analysis indicated slightly more immunoreactive fibronectin in the 10-wk old animals (Fig. $4 \mathrm{~B}$ ), densitometric analysis suggesting a 1.8 -fold difference in relative intensity. At 20 and $40 \mathrm{wk}$ of age the changes were less obvious. Differences between age-matched animals at any of the ages examined did not appear nearly as striking as those observed with the DOC/salt-treated animals. However, if the extracts from the same strain were compared as a function of age (Fig. $4 \mathrm{C}$ ), there was a noticeable increase in immunodetectable fibronectin between 10 and 40-wk old animals both in the Wistar and the SHR, consistent with the biosynthetic data shown in Table III. The age-dependent increase did appear more pronounced in the SHR.

\section{Discussion}

The in vitro studies presented in this study used metabolically intact aortic rings to compare the biosynthesis of fibronectin in normotensive and hypertensive rat models. The aortic rings provided a useful metabolic preparation to assess both total protein biosynthesis and the specific formation of immunoprecipitable fibronectin. Steady-state mRNA levels for aortic fibronectin were recently shown to be increased during the course of experimental or genetic hypertension in rats, concomitant with increases in immunodetectable fibronectin (19). The general findings of increases in steady-state mRNA, fibronectin biosynthesis, and immunoreactive fibronectin in the different models suggest that transcriptional regulation is involved in mediating the change in aortic fibronectin expression. In reviewing published literature on factors influencing the biosynthetic rate of fibronectin in cultured cells, it was suggested that fibronectin mRNA was the major determinant (24). Although it is possible that posttranscriptional modifications at the level of protein synthesis, covalent modification, matrix assembly, or degradation could also influence tissue fibronectin levels, it seems clear that the increased aortic fibronectin mRNA levels induced during experimental hypertension can lead to increased aortic fibronectin.

Aortic rings prepared using techniques similar to those described in this study have become a well established experimental model to study the functional characteristics of vascular tissue with respect to reactivity or endothelial dependent responses $(25,26)$. Although the importance of endothelial integrity and tissue handling was emphasized with respect to glucose metabolism (27) and recently by us with regard to fatty acid oxidation (28), relatively few studies have used such preparations for studies of protein biosynthesis despite the ability of carefully prepared tissue samples to retain pharmacological characteristics in vitro for time periods exceeding $24 \mathrm{~h}$. Attempts were made to minimize differences both in handling of the animals before killing them and in manipulating the tissue segments before incubation. The aortic segments proved to be metabolically intact, and overall, the reproducibility of the procedure with respect to protein biosynthesis and fibronectin for- 
mation was sufficient to make quantitative comparisons between groups.

Total protein biosynthesis in aortic rings from normotensive and hypertensive models was similar in these in vitro studies when normalized to total protein content. This was somewhat surprising since aortic hypertrophy is a consistent sequela to the hypertensive state (29), with hypertrophy often being defined as an increase in protein per cell. Using cultured vascular smooth muscle cells, studies have shown that incubation with angiotensin II leads to a hypertrophic response that includes increased protein biosynthesis $(30,31)$. One explanation for the similarity in protein biosynthesis between rings could be that the rings are no longer subjected to mechanical forces that exist in vivo, and increased wall tension could be a factor mediating the biochemical differences observed in vivo. Concerning the effect of mechanical forces on protein metabolism, increased mechanical tension on isolated pulmonary artery segments caused increased biosynthesis of collagen and elastin (32) and studies using cultured smooth muscle cells showed that collagen biosynthesis was increased by cyclic stretching (33).

The differences in aortic fibronectin biosynthesis between control and hypertensive groups were most obvious in the DOC/salt model, and the approximately sixfold increase in biosynthetic rate after $21 \mathrm{~d}$ of treatment is quantitatively similar to the previously reported difference in fibronectin steady-state mRNA levels (19). Because of the protocol used, we cannot completely rule out the possibility that changes in amino acid uptake, precursor pools, or fibronectin degradation account for the increase in net incorporation of labeled methionine into immunoprecipitable fibronectin. However, the absence of significant differences in net incorporation into total protein does minimize the possibility that differences in uptake or precursor pools affected the results. With respect to fibronectin degradation, we have not directly compared treated and control animals, but in separate experiments using normal aortic tissue, a pulse-chase protocol indicated that the amount of labeled methionine incorporated into fibronectin from the SDS extract during a 4-h pulse was unchanged after a 2,6 , or 24-h chase period. Thus the pool of newly synthesized fibronectin being measured in these studies has a relatively slow turnover.

These data provide evidence that transcriptional events influenced fibronectin biosynthesis in the aorta, and also reinforce the probability that the in vitro biosynthetic data reflect events occurring in vivo. What was unexpected was the finding that immunoreactive fibronectin was increased to such a significant extent, even after only $7 \mathrm{~d}$ of DOC/salt treatment, when blood pressure changes were modest. The immunochemical assays measure fibronectin that might originate from circulating plasma as well as from aortic synthesis. Unless fibronectin turnover is rapid in aortic tissue, the large difference between treated and control groups could reflect increased insudation of plasma fibronectin in addition to endogenously produced protein. Using the monoclonal antibody to the alternatively spliced form of fibronectin containing the EIIIA insert, which is known not to circulate in plasma, we were able to show significant increases in endogenously produced material. However, this does not rule out the possibility of infiltration of plasma fibronectin secondary to DOC/salt treatment.

The changes observed with age also showed a reasonable correlation between fibronectin biosynthesis and the previously reported data (19) on steady-state mRNA levels, which increased progressively between 5 and 40 wk of age. In general, the increased biosynthetic rate for fibronectin with age in both Wistar and SHR was consistent with steady-state mRNA data (19), and with the findings using Western blot analysis, where increases were seen in the 40-wk old animals compared to those of 10 and 20 wk of age. The similar fibronectin biosynthetic rates between age-matched normotensive and hypertensive animals were in contrast to our previously reported steadystate mRNA data, which suggested approximately two to threefold greater levels in hypertensive animals at the ages studied. This could indicate that posttranscriptional regulatory mechanisms may influence fibronectin biosynthesis as the animals age and the composition of the extracellular matrix changes, or it may reflect different regulatory mechanisms for fibronectin expression in the SHR as compared to the Wistar. Interestingly, comparisons of immunodetectable fibronectin between the age-matched strains were more consistent with the biosynthetic data than that for steady-state mRNA, further suggesting the possibility of posttranscriptional control.

Fibronectin is generally considered to have an important role in the process of wound repair, and there are analogies between the vascular response to hypertension and wound repair. Of potential relevance is the regulatory role of growth factors in both processes. Transforming growth factor- $\beta$ (TGF$\beta$ ) was shown to influence fibronectin expression in cultured fibroblasts $(34,35)$ and is generally thought to influence the wound repair process in vivo, in part by its effects on the extracellular matrix. However, TGF- $\beta$ did not influence collagen or fibronectin expression in cultured smooth muscle cells $(36$, $37)$. We have shown that TGF- $\beta$ mRNA levels were increased in aortae of rats treated with DOC/salt (38) suggesting the possibility of autocrine or paracrine influences on aortic extracellular matrix, but there is no definitive study to date showing that TGF- $\beta$ modulates aortic gene expression in vivo. Although growth factors clearly have a role in influencing fibronectin expression, many other regulatory agents have been proposed and it is premature to state whether hemodynamic forces, paracrine and autocrine regulation, or intracellular regulatory events have a predominant role within the vessel wall. However, the use of metabolically intact aortic rings that maintain cell to cell and cell to extracellular matrix interactions in a manner which is perhaps more physiological than that present in cell culture, offers a potentially valuable system for determining the factors regulating fibronectin biosynthesis.

\section{Acknowledgments}

The authors thank Dr. Luciani Zardi for providing the monoclonal antibody to fibronectin used in this study.

This work was supported by National Institutes of Health grants HL-18318 and HL-31195. Dr. Takasaki was supported in part by grants 63044118 and 01044120 from Joint Research, the International Scientific Research Program of the Ministry of Education, Science, and Culture, Japan.

\section{References}

1. Thyberg, J., U. Hedin, M. Sjolund, L. Palmberg, and B. A. Bottger. 1990. Regulation of differentiated properties and proliferation of arterial smooth muscle cells. Arteriosclerosis. 10:966-990.

2. Ross, R. 1986. The pathogenesis of atherosclerosis-an update. N. Engl. J. Med. 314:488-500.

3. Gabbiani, G., O. Kocher, W. S. Bloom, J. Vandekerckhove, and K. Weber. 1984. Actin expression in smooth muscle cells of rat aortic intimal thickening, 
human atheromatous plaque, and cultured rat aortic media. J. Clin. Invest. 73:148-152.

4. Chamley-Cambell, J., G. R. Cambell, and R. Ross. 1979. The smooth muscle cell in culture. Physiol. Rev. 59:1-61.

5. Hedin, U., B. A. Bottger, E. Forsberg, S. Johansson, and J. Thyberg. 1988. Diverse effects of fibronectin and laminin on phenotypic properties of cultured arterial smooth muscle cells. J. Cell Biol. 107:307-319.

6. Madri, J. A., B. M. Pratt, and A. M. Tucker. 1988. Phenotypic modulation of endothelial cells by transforming growth factor $\beta$ depends upon the composition and organization of the extracellular matrix. J. Cell Biol. 106:1375-1384.

7. Madri, J. A., M. A. Reidy, O. Kocher, and L. Bell. 1989. Endothelial cell behavior after denudation injury is modulated by transforming growth factor- $\beta 1$ and fibronectin. Lab. Invest. 60:755-765.

8. Ingber, D. E. 1990. Fibronectin controls capillary endothelial cell growth by modulating cell shape. Proc. Natl. Acad. Sci. USA. 87:3579-3583.

9. Jensen, B. A., B. Holund, and I. Clemmensen. 1983. Demonstration of fibronectin in normal and injured aorta by an indirect immunoperoxidase technique. Histochemistry. 77:395-403.

10. Rasmussen, L. H., C. Garbarsch, J. Chemnitz, B. C. Christensen, and I. Lorenzen. 1989. Injury and repair of smaller muscular and elastic arteries, immunohistochemical demonstration of fibronectin and fibrinogen/fibrin and their degradation products in rabbit femoral and common carotid arteries following a dilatation injury. Virchows Archiv. A Pathol. Anat. Histopathol. 415:579-585.

11. Orekhov, A. N., E. R. Andreeva, B. V. Shekhonin, V. V. Tertov, and V. N Smirnov. 1984. Content and localization of fibronectin in normal intima, atherosclerotic plaque, and underlying media of human aorta. Atherosclerosis. 53:213219.

12. Smith, E. B., and C. Ashall. 1986. Fibronectin distribution in human aortic intima and atherosclerotic lesions, concentration of soluble and collagenase-releasable fractions. Biochim. Biophys. Acta. 880:10-15.

13. Phan-Thanh, L., J. Robert, J. C. Derouette, and J. Labat-Robert. 1987. Increased biosynthesis and processing of fibronectin in fibroblasts from diabetic mice. Proc. Natl. Acad. Sci. USA. 84:1911-1915.

14. Rasmussen, L. M., and L. Heickendorff. 1989. Quantification of fibronectin in extracts of human aortae by an ELISA. Scand. J. Clin. Lab. Invest. 49:205210.

15. Glukhova, M. A., M. G. Frid, B. V. Shekhonin, T. D. Vasilevskaya, J. Grunwald, M. Saginati, and V. E. Koteliansky. 1989. Expression of extradomain A fibronectin sequence in vascular smooth muscle cells is phenotype dependent. J. Cell Biol. 109:357-366

16. Wolinsky, H. 1970. Response of the rat aortic media to hypertension. Morphological and chemical studies. Circ. Res. 26:507-522.

17. Ooshima, A., G. C. Fuller, G. J. Cardinale, S. Spector, and S. Udenfriend. 1974. Increased collagen synthesis in blood vessels of hypertensive rats and its reversal by antihypertensive agents. Proc. Natl. Acad. Sci. USA. 71:3019-3023.

18. Brecher, P., C. T. Chan, C. Franzblau, B. Faris, and A. V. Chobanian 1978. Effects of hypertension and its reversal on aortic metabolism in the rat. Circ. Res. 43:561-569.

19. Takasaki, I., A. V. Chobanian, R. Sarzani, and P. Brecher. 1990. Effect of hypertension on fibronectin expression in the rat aorta. J. Biol. Chem. 265:21935-21939.

20. Sarzani, R., K. P. Claffey, A. V. Chobanian, and P. Brecher. 1988. Hypertension induces tissue-specific gene suppression of a fatty acid binding protein in rat aorta. Proc. Natl. Acad. Sci. USA. 85:7777-7781.
21. Haudenschild, C. C., M. F. Prescott, and A. V. Chobanian. 1980. Effects of hypertension and its reversal on aortic intima lesions of the rat. Hypertension (Dallas). 2:33-44.

22. Laemmli, U. K. 1970. Cleavage of the structural proteins during the assembly of the head of bacteriophage T4. Nature (Lond.). 227:680-685.

23. Borsi, L., B. Carnemolla, P. Castellani, C. Roselli, D. Vecchio, G. Allemanni, S. E. Chang, J. Taylor-Papadimitriou, H. Pande, and L. Zardi. 1987. Monoclonal antibodies in the analysis of fibronectin isoforms generated by alternative splicing of mRNA precursors in normal and transformed human cells. $J$. Cell Biol. 104:595-600.

24. Hynes, R. O. 1990. Fibronectins. Springer-Verlag New York Inc. p. 319.

25. Gryglewski, R. J., R. M. Botting, and J. R. Vane. 1988. Mediators produced by the endothelial cell. Hypertension (Dallas). 12:530-548.

26. Jones, A. W., B. B. Geisbuhler, S. D. Shukla, and J. M. Smith. 1988 Altered biochemical and functional responses in aorta from hypertensive rats. Hypertension (Dallas). 11:727-634.

27. Morrison, A. D., L. Berwick, L. Orci, and A. I. Winegrad. 1976. Morphology and metabolism of an aortic intima-media preparation in which an intact endothelium is preserved. J. Clin. Invest. 57:650-660.

28. Takasaki, I., R. A. Cohen, A. V. Chobanian, and P. Brecher. 1990. Effect of endothelial cell denudation on fatty acid metabolism by rabbit aorta. Am. J. Physiol. 259 (Heart Circ. Physiol. 28):H442-H447.

29. Folkow, B. 1982. Physiological aspects of primary hypertension. Physiol. Rev. 62:347-504

30. Geisterfer, A. A. T., M. J. Peach, and G. K. Owens. 1988. Angiotensin II induces hypertrophy, not hyperplasia, of cultured rat aortic smooth muscle cells. Circ. Res. 62:749-756.

31. Berk, B. C., V. Vekshtein, H. M. Gordon, and T. Tsuda. 1989. Angiotensin II-stimulated protein synthesis in cultured vascular smooth muscle cells. $\boldsymbol{H y}$ pertension (Dallas). 13:305-314.

32. Tozzi, C. A., G. J. Poiani, A. M. Harangozo, C. D. Boyd, and D. J. Riley. 1989. Pressure-induced connective tissue synthesis in pulmonary artery segments is dependent on intact endothelium. J. Clin. Invest. 84:1005-1012.

33. Leung, D. Y., S. Glagov, and M. B. Matthews. 1976. Cyclic stretching stimulates synthesis of matrix components by arterial smooth muscle cells in vitro. Science (Wash. DC). 191:475-477.

34. Ignotz, R. A., and J. Massague. 1986. Transforming growth factor- $\beta$ stimulates the expression of fibronectin and collagen and their incorporation into the extra-cellular matrix. J. Biol. Chem. 261:4337-4345.

35. Roberts, C. J., T. M. Birkenmeier, J. J. McQuillan, S. K. Akiyama, S. S. Yamada, W. T. Chen, K. M. Yamada, and J. A. McDonald. 1988. Transforming growth factor- $\beta$ stimulates the expression of fibronectin and of both subunits of the human fibronectin receptor by cultured human lung fibroblasts. J. Biol. Chem. 263:4586-4592.

36. Penttinen, R. P., S. Kobayashi, and P. Bornstein. 1988. Transforming growth factor $\beta$ increases mRNA for matrix proteins both in the presence and in the absence of changes in mRNA stability. Proc. Natl. Acad. Sci. USA. 85:11051108 .

37. Liau, G., and L. M. Chan. 1989. Regulation of extracellular matrix RNA levels in cultured smooth muscle cells, relationship to cellular quiescence. J. Biol. Chem. 264:10315-10320.

38. Sarzani, R., P. Brecher, and A. V. Chobanian. 1989. Growth factor expression in aorta of normotensive and hypertensive rats. J. Clin. Invest. 83:14041408 . 